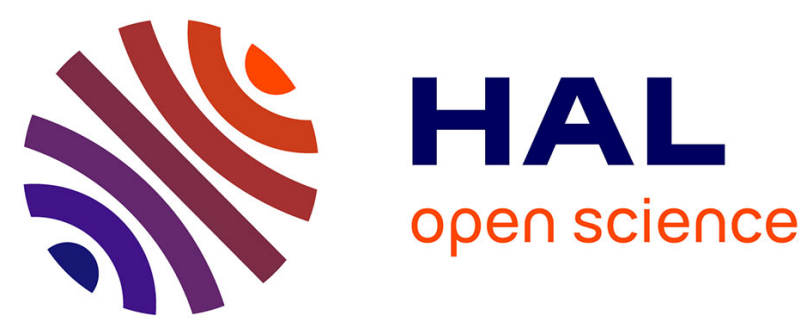

\title{
A SUGGESTION OF NOISE EXPERIMENT FOR SHOWING BALLISTIC TRANSPORT
}

P. Hesto, J. Vaissière, D. Gasquet, R. Castagné, J.-P. Nougier

\section{To cite this version:}

P. Hesto, J. Vaissière, D. Gasquet, R. Castagné, J.-P. Nougier. A SUGGESTION OF NOISE EXPERIMENT FOR SHOWING BALLISTIC TRANSPORT. Journal de Physique Colloques, 1981, 42 (C7), pp.C7-235-C7-241. 10.1051/jphyscol:1981728 . jpa-00221665

\section{HAL Id: jpa-00221665 https://hal.science/jpa-00221665}

Submitted on 1 Jan 1981

HAL is a multi-disciplinary open access archive for the deposit and dissemination of scientific research documents, whether they are published or not. The documents may come from teaching and research institutions in France or abroad, or from public or private research centers.
L'archive ouverte pluridisciplinaire HAL, est destinée au dépôt et à la diffusion de documents scientifiques de niveau recherche, publiés ou non, émanant des établissements d'enseignement et de recherche français ou étrangers, des laboratoires publics ou privés. 


\title{
A SUGGESTION OF NOISE EXPERIMENT FOR SHOWING BALLISTIC TRANSPORT
}

\author{
P. Hesto, J.C. Vaissière ${ }^{*}, D$. Gasquet ${ }^{*}$, R. Castagné and J.P. Nougier ${ }^{*}$ \\ Institut d'EZectronique Fondamentale, Laboratoire associé au C.N.R.S., LA 22 \\ et Greco Microondes, Université Paris XI, 91405 Orsay, France \\ * Université des Seiences et Techniques du Languedoc, Centre d'Etudes d'Electro- \\ nique des Solides, Laboratoire associé au C.N.R.S., LA 21 et Greco Microondes, \\ 34060 Montpellier Cedex, France
}

Résumé : La plupart des méthodes expérimentales tendant à mettre en évidence Te régime quasi ballistique sont fondées sur la mesure de la survitesse. Nous suggérons une expérience permettant de mesurer la variation de bruit. Pour cela nous mettons en oeuvre une nouvelle méthode théorique de modélisation du courant de bruit $S_{i g}$ dans la grille des FET, qui permet de montrer que $S_{i G}$ est relié à la tempêrature de bruit du canal actif sous la grille.

Abstract : Most of the experimental methods intending to exhibit quasi ballistic regimes involve the measurement of velocity overshoot. We suggest an experiment in which the variation of the noise would be measured. For this purpose we set up a new theoretical method for modeling the noise current $S_{i g}$ in the gate of FETs, which shows that $S_{i_{G}}$ is related to the noise temperature of the active channel under the gate.

\section{INTRODUCTION}

In very short devices, the carriers, when flowing from one electrode to the other one, have no time to undergo enough scattering events so as to reach their stationary state velocity. The transport is then said to be ballistic or quasi ballistic. When the electric field is high, the acceleration during the free paths overcomes the deceleration during the few scattering events, so that the carriers are under velocity overshoot conditions. The d.c. characteristic of the device is then a steady regime in which every carrier is in non steady state. An important question is to estimate the effect of the velocity overshoot on the behaviour of the device, but a still more basic question is to get sure that this phenomenon actually occurs. 
Many authors theoretically predicted ballistic transport in many semiconductors, by solving the transient Boltzmann equation. Many experiments are now designed to bring an experimental evidence of this phenomenon. Most of them consist in evidencing velocity overshoot. They use I-V characteristics of short devices [ 1 ] (al though some problems may arise using such a technique. [2]), microwave techniques $[3]$, or optical excitations [ 4$][5]$.

The purpose of this paper is to suggest the possibility of measuring the fluctuations of the velocity instead of its average value, since under ballistic behaviour, when no or few collisions occur, the fluctuations of the velocity are expected to diminish. The basic idea is then to measure, in the gate of a field effect transistor, the noise current induced by the fluctuations of the velocities of the carriers in the channel : the gate behaves like a probe and only the fluctuations in the active channel, under the gate, are detected by this probe, the "parasitic region" between the source and the gate and between the gate and the drain have no significant effect. Thus; when the length of the transistor is reduced (submicron FET), the electric field is high underneath the gate, the carriers are under quasi ballistic conditions in the active channel, so that the noise current of the gate is expected to diminish with respect to the one which could be observed in long FETs.

We shall briefly recall (section 2) the new method developped for getting the impedance field, which is particularly well suited for modelling the noise of FETs $[7][8]$, then use this method for giving a method to determine the noise induced in the gate (section 3 ), and give the results for a simplified but realistic mode1 (section 4).

\section{DETERMINATION OF THE IMPEDANCE FIELD}

Let us consider a FET (Fig. 1) where $x$ is along a d.c. current line. At abscisse $x$, the potential is $V(x)$, and the current flowing through equipotential surface $V(x)$ is $I(x)$. The d.c. current is given by $I(x)=f[V(x)]$. Writing $V(x)=V_{0}(x)+\delta V(x)$ exp $i \omega t$ and $I(x)=I_{0}(x)+\delta I(x)$ exp i $\omega t$, the first order terms of the conduction equations give

$$
\delta I(x)=\hat{\mathscr{L}}_{\delta V}(x)
$$

where $\hat{\mathscr{L}}$ is a linear operator. Let $z\left(x, x^{\prime}\right)$ be the Green function of $\hat{\mathscr{L}}$, defined as:

$$
\widehat{\mathscr{Z}} \mathcal{Z}\left(x, x^{\prime}\right)=\delta\left(x-x^{\prime}\right)
$$

where $\delta\left(x-x^{\prime}\right)$ is the Dirac function. Eqs. (1) and (2) give : 


$$
\delta V(x)=\int_{0}^{L} Z\left(x, x^{\prime}\right) \delta I\left(x^{\prime}\right) d x^{\prime}
$$

of course $z\left(x, x^{\prime}\right)$ may depend on $w$. By setting $x=L$ in eq. (3), one gets the voltage variation $\delta V(L)$ between the source and the drain, produced by a current $\delta I\left(x^{\prime}\right)$ in the slice $d x^{\prime}$ : the ratio $Z\left(x=L, x^{\prime}\right)$ is the impedance field $[7][8]$.

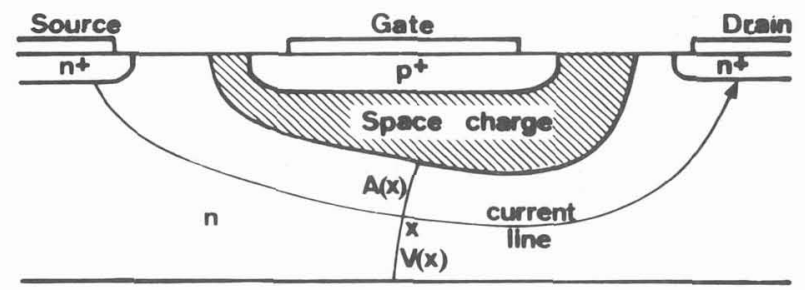

Figure 1 : Example of structure of a FET (the figure shows a JG.FET, but a similar representation could have been made for a MOS FET).

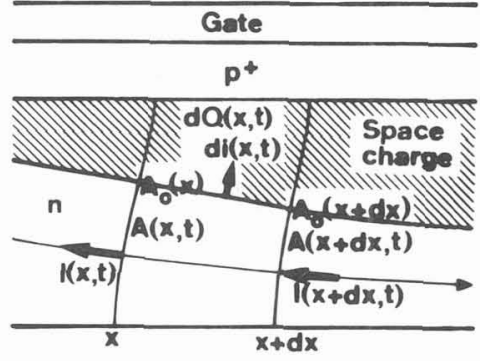

Figure 2 : Charge and current balance in a slice of the channel.

\section{NOISE CURRENT INDUCED IN THE GATE}

Due to the noise sources inside the channel, the potential $V(x, t)$ of the equipotential surface crossing the current line at abscissa $x$ fluctuates around its average (=d.c.) value $V_{0}(x)$, thus producing a fluctuation of the extension of the space charge and hence of the channel of area $A(x, t)$. The variation of the charge in the space charge region produces a variation of the current in the gate, through the capacitive coupling between the gate and the channel.

For getting this current, one writes the conservation of the current through a slice of the channel of thickness $d x$ (see Fig. 2) :

$$
d i(x, t)=\partial d Q(x, t) / \partial t \quad \text { where } d Q(x, t)=q N_{D}\left[A_{0}(x)-A(x, t)\right] d x
$$

Since $A(x, t)=A[V(x, t)]$, eq. (4) gives :

$$
d i(x, t)=-q N_{D}(d A / d V)_{0, x}(\partial V(x, t) / \partial t) d x
$$


where the subscripts 0 and $x$ mean the d.c. value at point $x$. When setting $V(x, t)=V_{0}(x)+\delta V(x)$ exp iwt, thus $d i(x, t)=d i_{0}(x)+\delta d i(x)$ exp $i \omega t$, one gets (in practice the leakage d.c. current $d i_{0}(x)$ can be neglected) :

$$
\delta d i(x)=-q N_{D} i \omega(d A / d V)_{0, x} \delta V(x) d x
$$

The a.c. gate current is then obtained by integrating eq. (6) over the total length of the FET :

$$
\delta i_{G}=-i \omega q N_{D} \int_{0}^{L}(d A / d V)_{O, x} \delta V(x) d x
$$

that is, taking into account eq. (3) :

$$
\delta i_{G}=-i \omega q N_{D} \int_{0}^{L} \int_{0}^{L}(d A / d V)_{0, x} Z\left(x, x^{\prime}\right) \delta I\left(x^{\prime}\right) d x d x^{\prime}
$$

For getting the spectral density $S_{i_{G}}$ of the fluctuation of the gate current in the bandwidth $\Delta f[8]$, one multiplies $\delta i_{G}$ by $i$ ts complex conjugate $\delta i_{G}^{*}$ and :

$$
\begin{gathered}
\delta i_{G} \cdot \delta i_{G}^{*}=S_{i_{G}} \Delta f \text {, so that eq. (8) gives: } \\
s_{i_{G}}=\omega^{2} q^{2} N_{D}^{2} \int_{0}^{L} \int_{0}^{L} \int_{0}^{L} \int_{0}^{L}\left(\frac{d A}{d V}\right)_{0, x} Z\left(x, x^{\prime}\right)\left(\frac{d A}{d V}\right)_{o, u}^{*} Z^{*}\left(u, u^{\prime}\right) S_{I}\left(x^{\prime}, u^{\prime}\right) d x d x^{\prime} d u d u^{\prime}
\end{gathered}
$$

Now the noise sources at two different points are uncorrelated, and the noise source $K\left(x^{\prime}\right)$ is defined $[8]$ as

$$
S_{I}\left(x^{\prime}, u^{\prime}\right)=A\left(x^{\prime}\right) K\left(x^{\prime}\right) \delta\left(x^{\prime}-u^{\prime}\right)
$$

Integrating eq. (9) over $u^{\prime}$ gives, taking into account eq. (10) :

$$
s_{i_{G}}=w^{2} q^{2} N_{D}^{2} \int_{0}^{L} \int_{0}^{L} \int_{0}^{L}\left(\frac{d A}{d V}\right)_{0, x} Z\left(x, x^{\prime}\right)\left(\frac{d A}{d V}\right)_{0, u}^{*} Z^{*}\left(u, x^{\prime}\right) A\left(x^{\prime}\right) K\left(x^{\prime}\right) d x d x^{\prime} d u
$$

Eq. (11) can be written :

$$
\left\{\begin{array}{l}
S_{i_{G}}=\int_{0}^{L} A\left(x^{\prime}\right) K\left(x^{\prime}\right)\left|\hat{Z}\left(x^{\prime}\right)\right|^{2} d x^{\prime} \\
\hat{Z}\left(x^{\prime}\right)=w q N_{D} \int_{0}^{L}\left(\frac{d A}{d V}\right)_{0, x} Z\left(x, x^{\prime}\right) d x
\end{array}\right.
$$

Comparing eq. (12) with the usual one dimensional expressions for the noise [8], it can be seen that $\hat{Z}\left(x^{\prime}\right)$ is a "transfer field", analogous to the impedance fie $] d$ of Shockley et al. [9].

Remark : the cross correlation between the gate current and the drain voltage can be obtained by multiplying $\delta i_{G}$, given by eq. (8), by $\delta V_{D}^{*}$ obtained by 
setting $x=L$ in eq. (3), which gives, taking into account eq. (10) :

$$
s_{i_{G} V_{D}}=-i \omega q N_{D} \int_{0}^{L} \int_{0}^{L}\left(\frac{d A}{d V}\right)_{0, x} Z\left(x, x^{\prime}\right) Z^{*}\left(L, x^{\prime}\right) K\left(x^{\prime}\right) A\left(x^{\prime}\right) d x d x^{\prime}
$$

Two important results can be derived from eqs. (12) and (13) :

a) The noise is proportional to $\omega^{2}$, resulting on the capacitive coupling, so that it can be expected to prevail at high frequency, over the other noise sources, which are constant or decreasing with increasing frequency. However this is very difficult to achieve experimentally $[10]$ due to the high impedance of the gate circuit.

b) Outside the active channel, the area is almost constant, so that $(d A / d V)_{0, x} \simeq 0$. Thus the contribution to $\widehat{Z}\left(x^{\prime}\right)$, and hence to the noise, is mainly due to the active channel, where the electric field is high. This will be even better evidenced on the model below.

\section{EXAMPLE}

This theory is applied in the present section to a simplified but still realistic model of FETs (JG.FETs - MOS FETs), valid up to the pinch off voltage of the static characteristics. We suppose that the charge accumulation in the channel is negligible, that is $n \simeq N_{D}$ (indeed $n$ lies in the range $0.9 N_{D}-1.1 N_{D}$ up to the pinch off voltage $[11])$. The velocity-field relation will be taken, in $S i$ channel FETs, as : $v(E)=-\mu_{0} E /\left(1-E / E_{c}\right)$. The minus signs result from the conventions we adopt : I is set positive, although $E$ is negative since $V_{D}>0$ for a $n$ type channel. The drain current is then given by

$$
I=-q N_{D} \mu_{0} E A /\left(1-E / E_{C}\right) \text { where } E=-d V / d x
$$

and the function $Z\left(x, x^{\prime}\right)$ is $[7]$, where the subscript 0 means the d.c. value and $H\left(x-x^{\prime}\right)$ is the step function :

$$
Z\left(x, x^{\prime}\right)=-\frac{E_{0}(x)}{I_{0}}\left[1-\frac{E_{0}\left(x^{\prime}\right)}{E_{c}}\right] H\left(x-x^{\prime}\right)
$$

Eq. (15) carried into eq. (13) gives

$$
\hat{z}\left(x^{\prime}\right)=-\left[1-\frac{E_{0}\left(x^{\prime}\right)}{E_{c}}\right] \frac{1}{I_{0}} \int_{x^{\prime}}^{L} E_{0}(x)(d A / d V)_{0, x} d x
$$

Now $-E_{0}(x) d x=d V_{0}(x)$ and $(d A / d V)_{0, x} d V_{0}(x)=d A(x)$, so that finally:

$$
\hat{Z}\left(x^{\prime}\right)=\frac{1}{I_{0}}\left[1-\frac{E_{0}\left(x^{\prime}\right)}{E_{c}}\right]\left[A(L)-A\left(x^{\prime}\right)\right]
$$

This expression carried into eq. (12) gives the noise current in the gate: 


$$
S_{i_{G}}=\frac{\omega^{2} q^{2} N_{0}{ }^{2}}{I_{0}^{2}} \int_{0}^{L} A\left(x^{\prime}\right) K\left(x^{\prime}\right)\left[1-\frac{E_{0}\left(x^{\prime}\right)}{E_{C}}\right]^{2}\left[A(L)-A\left(x^{\prime}\right)\right]^{2} d x^{\prime}
$$

The noise can be expressed using the noise temperature $T_{n}\left(x^{\prime}\right)$ instead of the noise source $K\left(x^{\prime}\right)$, since it was very recently shown $[12][8]$ that both were related though :

$$
K\left(x^{\prime}\right)=-4 k_{B} T_{n}\left(x^{\prime}\right) \operatorname{Re}[\delta j / \delta E]
$$

where $k_{B}$ is the Boltzmann constant, $j$ the current density and the minus sign follows from the convention of signs adopted for $E$ and I. Eq. (14), carried into eq. (18), then into eq. (17) gives:

$$
S_{i_{G}}=\frac{4 k_{B} \omega^{2} q^{3} N_{D}^{3} \mu_{0}}{I_{0}^{2}} \int_{0}^{L} T_{n}\left(x^{\prime}\right) A\left(x^{\prime}\right)\left[A(L)-A\left(x^{\prime}\right)\right]^{2} d x^{\prime}
$$

Eq. (19) clearly shows that the contribution of the regions outside the active channel is negligible since then $A\left(x^{\prime}\right) \simeq A(L)$. The noise current in the gate is then directly related to the noise temperature in the channel, thus confirming that the gate plays the role of a probe useful for testing the noise underneath.

Remark : the cross correlation between $i_{G}$ and $V_{D}$ can also be achieved : eq. (15) carried into eq. (14) gives:

$$
\begin{aligned}
& S_{j_{G} V_{D}}=-\frac{i \omega q N_{D}}{I_{0}{ }^{2}} E_{0}(L) \int_{0}^{L} d x^{\prime} K\left(x^{\prime}\right) A\left(x^{\prime}\right)\left[1-\frac{E_{0}\left(x^{\prime}\right)}{E_{C}}\right]^{2} \int_{X^{\prime}}^{L} d x\left(\frac{d A}{d V}\right)_{0, x} E_{0}(x) \\
& S_{i_{G} V_{D}}=\frac{i \omega q N_{D} E_{0}(L)}{I_{0}{ }^{2}} \int_{0}^{L} d x^{\prime} K\left(x^{\prime}\right) A\left(x^{\prime}\right)\left[A(L)-A\left(x^{\prime}\right)\right]\left[1-\frac{E_{0}\left(x^{\prime}\right)}{E_{C}}\right]^{2}
\end{aligned}
$$

Carrying eqs. (14) and (18) into (20), one gets :

$$
S_{i_{G} V_{D}}=\frac{4 i \omega q^{2} N_{D}^{2} k_{B} E_{0}(L)}{I_{0}{ }^{2}} \int_{0}^{L} T_{n}\left(x^{\prime}\right) A\left(x^{\prime}\right)\left[A(L)-A\left(x^{\prime}\right)\right] d x^{\prime}
$$

This expression is very similar to eq. (19), except that the integral involves $A(L)-A\left(x^{\prime}\right)$ instead of $\left[A(L)-A\left(x^{\prime}\right)\right]^{2}$, which means that the effects of the non active regions, outside the channel, is less damped for $S_{i_{G}} V_{D}$ than for $S_{i_{G}}$, which is normal since $V_{D}$ takes those regions into account.

\section{CONCLUSION}

We presented in this paper a new method for determining the noise current $S_{i_{G}}$ in the gate so as the cross correlation $S_{i_{G}} V_{D}$. Quite simple formulas were obtained on realistic models, and can be used for simulating the noise of actual devices and comparying it with experimental results. It was shown that the gate of a FET behaves like a probe, so that the noise current depends on the noise temperature of the active channel. 
In submicron FETs, the carriers undergo ballistic transport in the active channel, so that one would expect the diminution of the noise since less scattering events occur. This effect could likely be evidenced at temperature low enough for the Fermi energy level be about the impurity energy level : for example in $n-S i$ at $77 \mathrm{~K}$, part of the donors are ionized, and the electric field enhances impurity ionization through impact ionization or Poole Frenkel effect, thus producing a high noise temperature [ 13$]$, and one might think that its diminution, produced by quasi ballistic transport, could be observable.

\section{REFERENCES}

[1] L.F. EASTMAN, Experimental studies of ballistic electron transport in semiconductors, Journal de Physique, Proc. 3rd Int. Conf. on Hot Carriers in Semiconductors, Montpellier (France), 7-10 July 1981.

[ 2 ] J.R. BARKER, D.K. FERRY and H.L. GRUBIN, IEEE El. Dev. Lett. EDL 1, 209(1980).

[ 3 ] S.J. ALLEN, D.C. TSUI, F. DEROSA, K.K. THORNBER and B.A. WILSON, Direct measurement of velocity overshoot by hot electron, submillimeter wave conductivity in Si inversion layers, Journal de Physique, Proc. 3rd Int. Conf. on Hot Carriers in Semiconductors, Montpellier (France), 7-10 July 1981.

[ 4 ] S. LAVAL, C. BRU, R. CASTAGNE and C. ARNODO, GalTium Arsenide and Related Compounds 1980, Ed. H.W. Thim, Institute of Physics, Conf. Series $n^{\circ} 56$, London, p. 171, 1980.

[5] C.V. SHANK, R.L. FORK and B.I. GREENE, Picosecond nonequilibrium carrier transport in GaAs, Journa1 de Physique, Proc. 3rd Int. Conf. on Hot Carriers in Semiconductors, Montpellier (France), 7-10 July 1981.

[6] J. SHAH, investigation of hot electron relaxation with picosecond laser pulses, Journal de Physique, Proc. 3rd Int. Conf. on Hot Carriers in Semiconductors, Montpellier (France), 7-10 July 1981.

[7] J.P. NOUGIER, J.C. VAISSIERE and D. GASQUET, Proc. 6th Int. Conf. on Noise in Physical Systems (Washington, USA, 6-10 April 1981), to be published.

[8] J.P. NOUGIER, Modeling the noise of devices working under hot carrier conditions, invited paper, Proc. 6th Int. Conf. on Noise in Physical Systems (Washington, USA, 6-10 Apri1 1981), to be published.

[ 9 ] W. SHOCKLEY, J.A. COPELAND and R.P. JAMES, in Quantum Theory of Atoms, Molecules and the Solid State, P. Lowdin ed., Acad. Press, New York, 1966.

[ 10$]$ G. LECOY, D. RIGAUD and D. SODINI, Solid State Electron. 17, 11 (1974).

[11] D. SODINI, Thèse de Doctorat ès Sciences, Montpellier (1979)(available on request)

[12] J.P. NOUGIER, J.C. VAISSIERE, D. GASQUET and A. MOATADID, Noise sources of hot carriers in space charge regime, J. App 1. Phys., to be published.

[ 13 ] A. VAN DER ZIEL, R. JINDAL, S.K. KIM, H. PARK and J.P. NOUGIER, Sol.State Electron. 22, 177 (1979). 